\title{
O conteúdo tecnológico do comércio internacional brasileiro no período recente (1989-2005)*
}

\section{Introdução}

\author{
Wellington Pereira ${ }^{*}$ \\ Gabriel Porcile $^{* *}$
}

A década de noventa foi marcante para a economia brasileira no que se refere ao intenso número de transformações que ocorreram. Um aspecto relevante nesse contexto coube ao processo de abertura comercial (e financeira) que seguiu o panorama internacional de liberalização. Este cenário, em grande parte, agiu como uma das fontes indutoras de mudanças (em âmbito macroeconômico e setorial) que veio alterar o modo de atuação das empresas. Elas tiveram que se reorganizar e se reestruturar de modo a se inserirem no novo ambiente marcado por maiores graus de competição e exigibilidade pelo lado da oferta e da demanda final.

O Brasil, recorrentemente, foi classificado como um grande país ofertante de commodities e produtos básicos. No entanto, hoje é uma nação que, indiscutivelmente, possui além de suas riquezas naturais, uma estrutura industrial complexa, diversa, articulada e internacionalizada. Diferencia-se e distancia-se, assim, da grande maioria dos países em desenvolvimento (PED) que não detêm aparatos técnico-produtivos de tamanha magnitude ainda que longe de alguns casos emblemáticos de catching up industrial-tecnológico, como certos países do Leste Asiático. Ocorre que o desempenho do Brasil em termos das taxas de crescimento e do avanço tecnológico tem sido menor frente ao resto do mundo nas últimas duas décadas.

A tecnologia representa papel fundamental neste contexto. A relação entre o perfil competitivo dos segmentos produtivos de um país e o desenvolvimento e a absorção tecnológica são fatores chaves no processo de avanço para estágios superiores ou mais dinâmicos no que se refere à inserção no comércio internacional.

Tem sido crescente a assunção de que as diferenças internacionais nos domínios tecnológicos e nas capacidades internas de desenvolvimento e progresso técnico explicam o maior dinamismo nas exportações. Neste sentido, as transformações por que passam a estrutura produtiva de um país podem ser observadas sob a perspectiva dinâmica da relação

\footnotetext{
* Refere-se a uma síntese do capítulo segundo da dissertação de mestrado do autor (PEREIRA, 2007b).

* Mestre em Desenvolvimento Econômico (UFPR) e Analista do Banco Regional de Desenvolvimento do Extremo Sul (BRDE). Endereço eletrônico: wdspereira@yahoo.com.br

** Professor do Departamento de economia da UFPR. Endereço eletrônico: porcile@,ufpr.br
} 
entre tecnologia e comércio internacional. A presença de segmentos industriais nos ramos intensivos em tecnologia tem sido apontada pela literatura como a fonte do aumento de produtividade em diversos países. Ademais, as alterações positivas e propulsoras de dinamismo nas capacidades tecnológicas internas refletem seus bons resultados sobre o padrão de comércio exterior.

Entender o perfil da competitividade do Brasil tendo-se em mente o contexto de mudanças ocorridas nas relações econômicas nacionais tem sua importância, sobretudo, quando a questão tecnológica está presente e possibilita uma melhor compreensão do problema.

Além desta rápida introdução, o presente artigo apresenta na seqüência um exame sucinto dos fluxos comerciais do Brasil entre 1989 e 2005, de forma a identificar as principais características e o comportamento mediante níveis (grupos e categorias) tecnológicos ${ }^{45}$. Trabalha-se com o suposto de que os produtos com maior conteúdo tecnológico observados pelo lado das exportações podem indicar uma melhor qualificação da indústria local, e assim, poderão responder por uma melhor inserção nas relações de troca internacionais. Ademais, nos diversos exames realizados sob os distintos graus de incorporação tecnológica, são observadas as relações comerciais com os outros países a partir de seu respectivo grau de desenvolvimento - países desenvolvidos (PD) ou países em desenvolvimento (PED) - ou mesmo, dos blocos econômicos dos quais fazem parte.

\section{O comportamento dos fluxos comerciais por conteúdo tecnológico, 1989-}

\section{5}

Algumas das alterações que repercutiram no perfil do padrão de comércio exterior do período, tal como no formato de inserção internacional da economia brasileira, podem ser elencadas: inicialmente, a abertura econômica (comercial e financeira, em momentos e gradações diferentes); a estabilização monetária (Plano Real), sobrevalorização cambial funcionando como âncora para o novo plano econômico; queda da inflação e aumento da renda real da população; retorno substancial dos investimentos diretos estrangeiros (IDE), e com destaque, neste contexto, para os processos de privatização; boom de importações como respostas aos diversos processos apontados anteriormente e crescimento do déficit do

45 Os grupos tratam dos níveis tecnológicos mais agregados (Produtos Básicos, Baixa Tecnologia, Média Tecnologia e Alta Tecnologia); as categorias se referem à desagregação dos quatro casos anteriores. As categorias para cada grupo tecnológico são: a) Produtos Básicos - Produtos Primários, Produtos Agroflorestais, Outros baseados em recursos naturais; b) Baixa Tecnologia - Têxtil/Vestuário/Calçados e Outros de baixa tecnologia; c) Média Tecnologia - Automobilística, Processos e Engenharia; d) Alta Tecnologia - Eletroeletrônicos e Outros de alta tecnologia. 
balanço de pagamentos (devido tanto aos efeitos das relações comerciais de bens e serviços, como no que se refere aos fluxos de remessas de capitais crescentes) ${ }^{46}$.

A exposição do perfil do comércio exterior do período recente, que subseqüentemente é apresentada, leva em consideração dois fatores importantes já salientados por Gomes et al (2005). Um primeiro é que uma maior participação de produtos com elevado conteúdo tecnológico na pauta de exportações é resultado da maior e melhor capacitação da indústria, o que condiz com uma inserção internacional mais dinâmica. Um segundo fator trata do processo de integração. Como coloca Gomes et al (2005, p. 7-5), "se, por um lado a globalização é um processo sistêmico, que aprofunda os laços econômicos e financeiros internacionais, por outro, é, também, restrita e seletiva no que tange às capacidades tecnológicas dos diferentes países". Esse é um elemento importante no contexto de inserção internacional das diversas nações e não pode deixar de ser observado, sobretudo, no que se refere às possibilidades reservadas a alguns países em desenvolvimento, como o Brasil.

Figura 1. Exportações, importações e saldo (US\$ bi) por grupo tecnológico e evolução do câmbio real (1994=100), Brasil - 1989 a 2005
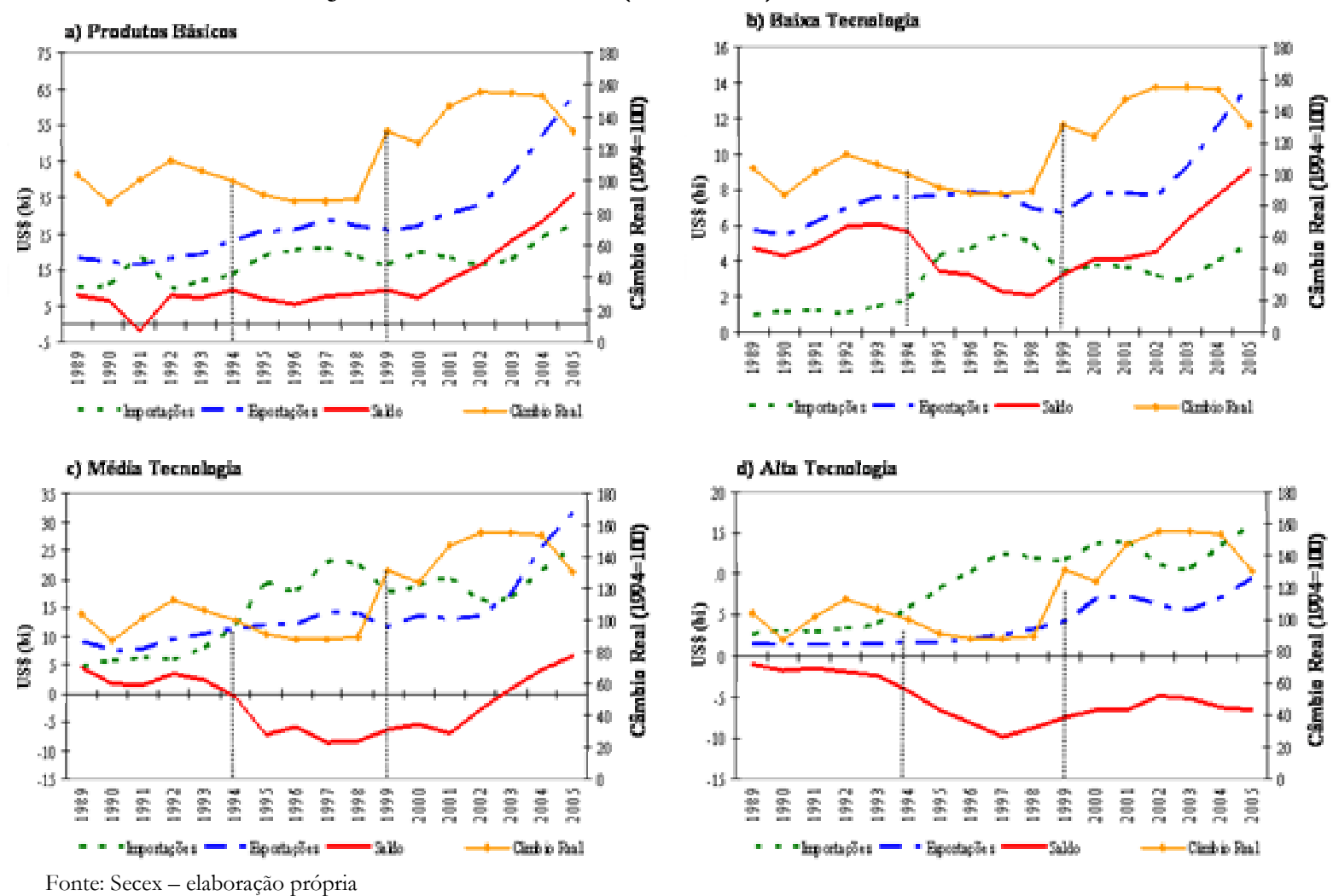

46 Uma apresentação deste debate pode ser encontrada em Pereira (2007a). 
Verificou-se que as alterações cambiais geraram impactos diferenciados sobre o comportamento dos grupos e das categorias tecnológicas. Enquanto os produtos básicos e os de baixa tecnologia conseguiram manter superávits entre o período de forte sobrevalorização cambial (1994-1998), os grupos de média e alta tecnologia responderam mais fortemente à situação, gerando déficits significativos. Diferentemente dos produtos básicos e de baixa tecnologia que tiveram superávits ao longo de todo o período selecionado para exame, os itens de média tecnologia só vieram a ter saldo positivo em sua balança comercial após 2003 como reflexo tardio da desvalorização ocorrida em 1999 e da melhoria dos canais de abertura e inserção dos produtos brasileiros no exterior. No caso de alta tecnologia o déficit permaneceu ao longo de todo o período (Figura 1).

Desta forma, o reflexo da evolução do câmbio real no perfil das relações comerciais dos grupos de itens pertencentes aos produtos básicos e de baixa tecnologia indicou um resultado diferente do que usualmente se esperaria. A impressão que se tem com base na evolução apresentada pela Figura 1 é que os produtos básicos se mostraram menos afetados pela sobrevalorização cambial até 1999, apesar do crescimento das importações. No entanto, estes produtos responderam afirmativamente com crescimento de suas exportações após a desvalorização. Apesar da similaridade em relação aos anos que seguem a partir de 2000, a diferença que fica marcada para produtos do grupo de BT é a resposta mais clara com o aumento das compras entre 1994 e 1999, com manutenção de vendas relativamente estáveis.

Uma hipótese que se aventa aqui trata do fato de que as commodities tendem, no que se refere aos produtos básicos, a ser menos sensíveis ao câmbio do que itens processados ou com nível de industrialização superior. Ademais, apesar do efeito positivo em termos de exportações que a desvalorização cambial pode ter gerado sobre estes grupos de produtos, é interessante atentar para o crescimento da demanda mundial de commodities, sobretudo pelos países asiáticos. Neste contexto, tais itens puderam desfrutar de uma melhor recepção internacional devido ao crescimento de seus preços.

Nas exportações (Figuras 2 e 3) o destaque se deu para sete categorias em especial: produtos primários, agroflorestais, outros baseados em recursos, outros de baixa tecnologia e as três categorias de média tecnologia - automobilística, processos e engenharia. Para todos esses casos o avanço que se verificou entre 1990 e 2005 foi bastante saliente. Nas importações (Figuras 2 e 3), o mapa dos segmentos que mais avançaram de forma característica a partir do programa de estabilização econômica de 1994 aponta as indústrias de processos, engenharia e eletro-eletrônica. Isso tende a nos indicar sinais das fragilidades presentes nestes segmentos 
industriais. No entanto, é importante salientar que embora muitos não conseguiram responder às novas condições competitivas, alguns implementaram processos de reestruturação e modernização da estrutura produtiva, após o choque de competitividade associado ao maior grau de abertura comercial.

\section{Figura 2. Exportações e importações (US\$ bi) por categorias} tecnológicas, Brasil - 1990, 1995, 2000 e 2005

a) 1990
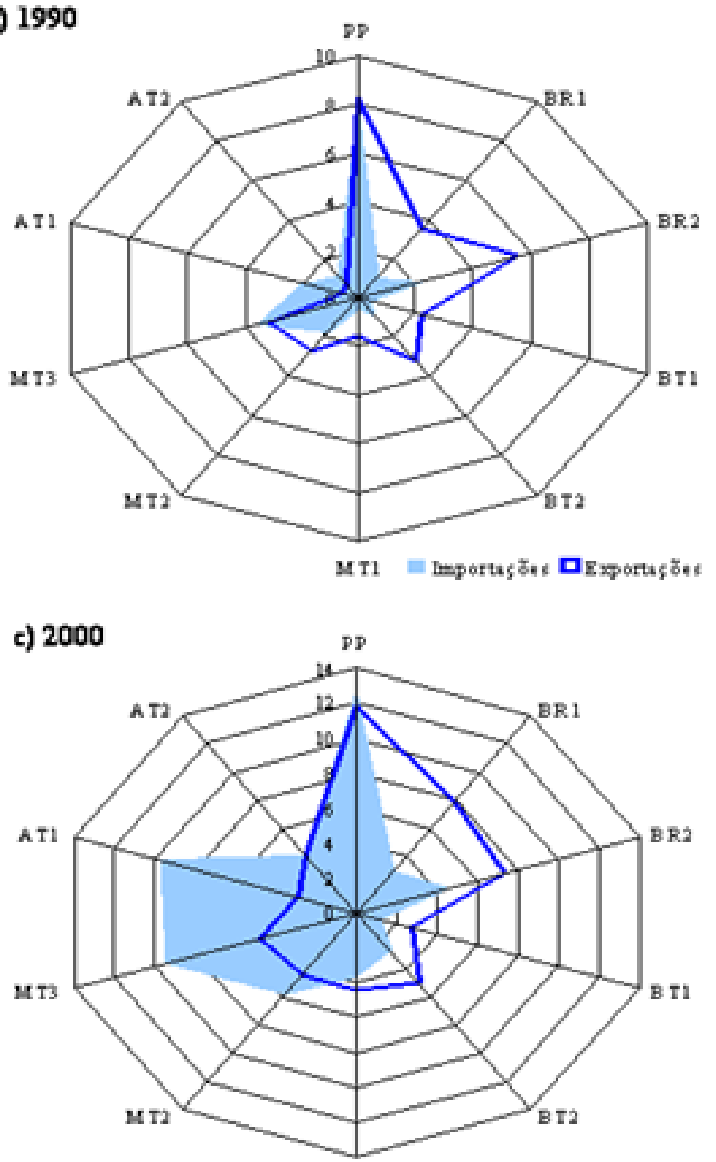

MT1 = แmport:

Legenda

$1-\mathrm{PP}$ = Produtos priminios

$2-B R 1=$ Produbs azroflowestais

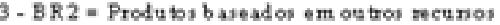

4- BT1 = Téxtillvestasiof alcados

5. BT2 = Ovtros produ tos de baixa tecnologia

Fonte: Secex - elaboração própria b) 1995

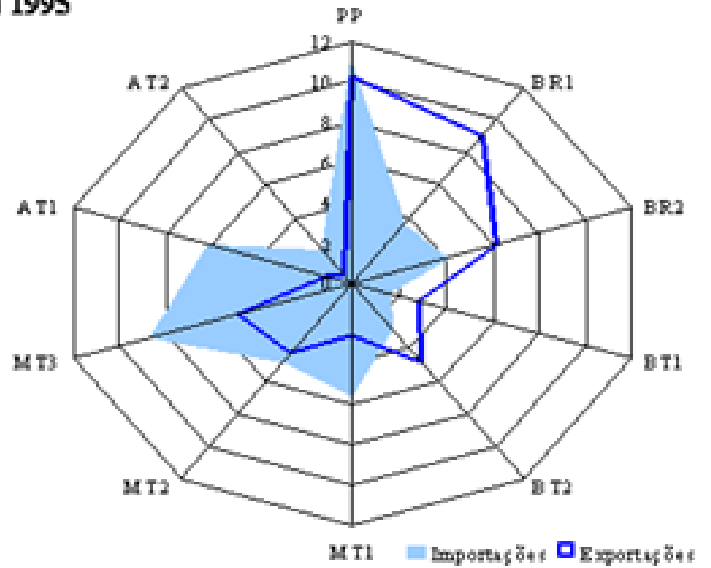

d) 2005

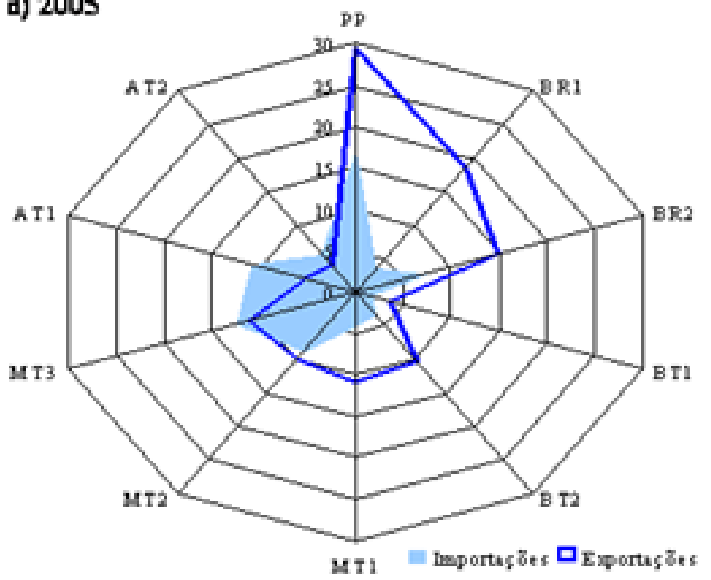

6 - MT I = Produtos aubmotivos

7 - MT2 = Industrias de processos (quimiea)

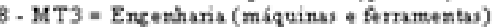

9. ATl = Eletrốnicos - Eliktricos

10 - A T2 = Outros produtos de alta tecnologia

A impressão evolutiva percebida a partir da figura 2 é a de que houve um esmorecimento da área preenchida pelas importações. $\mathrm{Na}$ verdade, o crescimento da escala detida pelas vendas de alguns dos segmentos que se destacam (PP, BR1 e BR2, sobretudo) acaba por dificultar uma visualização mais clara do papel das compras em 2005. Ocorre que as 
importações totais passam de US\$ 55 bi em 2000 para US\$ 73 bi em 2005, enquanto que nas exportações a mudança parte de um patamar muito similar ao das compras externas em 2000 para algo em torno de US\$118 bi no fim do período.

Figura 3. Saldo comercial (US\$ bi) por categorias tecnológicas, Brasil - 1990, 1995, 2000 e 2005

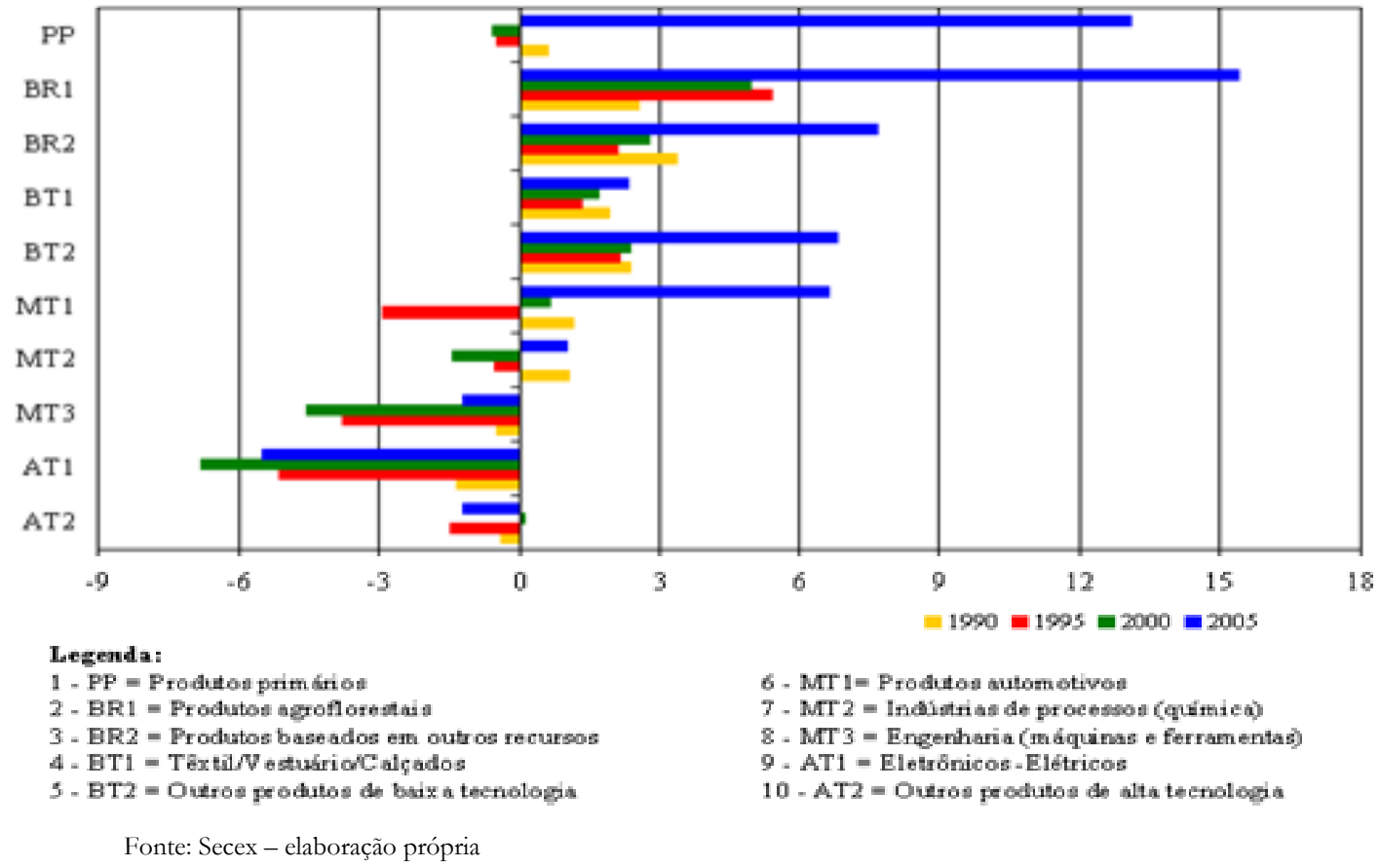

O cenário diagnosticado para os produtos de alta tecnologia demonstra um lado das deficiências tecnológicas do país que perduram ao longo do tempo, apesar de alguns avanços localizados (Figuras 3 e 4). Os déficits comerciais, existentes por todo o período relatado, foram exasperados com a sobrevalorização do câmbio de 1994, como parte do processo de estabilização econômica - o déficit foi multiplicado por oito vezes o seu valor verificado no início do período, então de um bilhão de dólares. O pico se deu em 1997, quando o valor atingiu US\$ 8,5 bilhões. As vendas, apesar de positivas e com tendência crescente, em nenhum momento foram mais expressivas que as compras internacionais. Foi o segmento de alta tecnologia aquele que mais sentiu o efeito-câmbio valorizado, gerando exportações líquidas negativas vultosas. Com a desvalorização em 1999, esse impacto foi amortizado, mas de maneira muito tímida, mantendo déficits altos, em torno de US\$ 6 bilhões até $2005^{47}$.

\footnotetext{
${ }^{47}$ Mesmo nos casos em que o país deteve déficits de forma destacável (itens da média e alta tecnologia), não se pode deixar de destacar a evolução das suas exportações, que não foram desprezíveis. Ademais, no que se refere à automobilística, nota-se que, a partir de 2000, superávits começam a ser registrados, e de maneira significativa (passa-se de uma cifra próxima US\$ 600 mi para US\$ 6 bi).
} 
Figura 4 - Saldo comercial (US\$ mi) dos grupos e das categorias tecnológicas por origem e destino dos fluxos, Brasil - 1990, 1995, 2000 e 2005

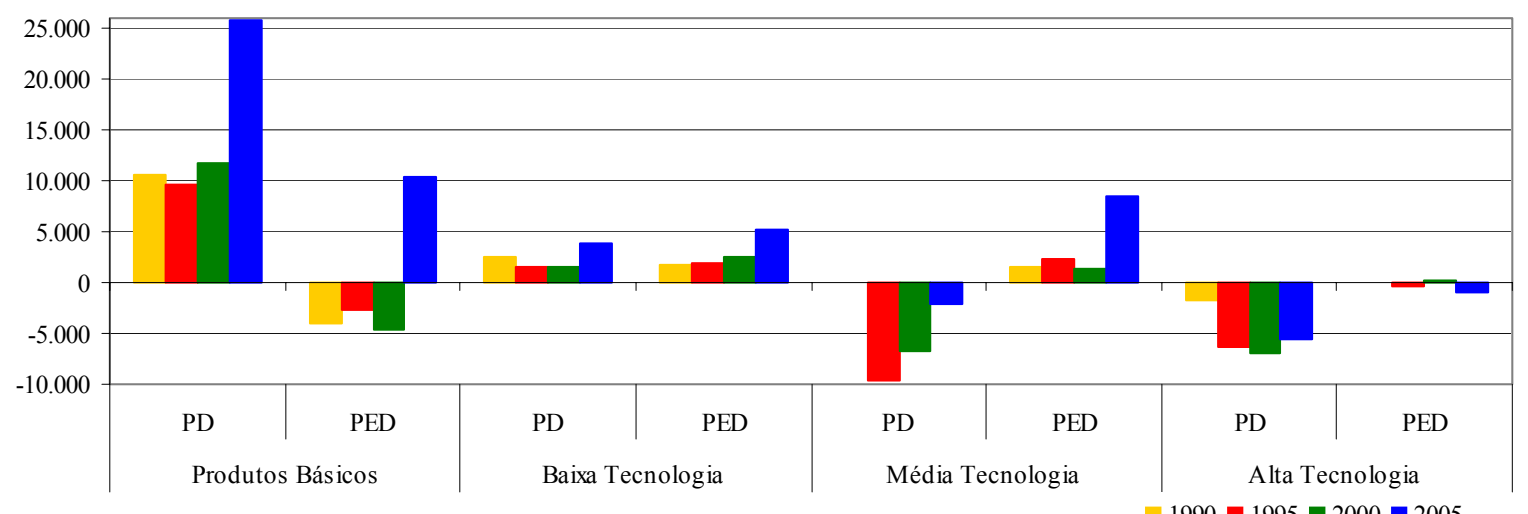

$1990 \square 1995 \square 2000 \square 2005$

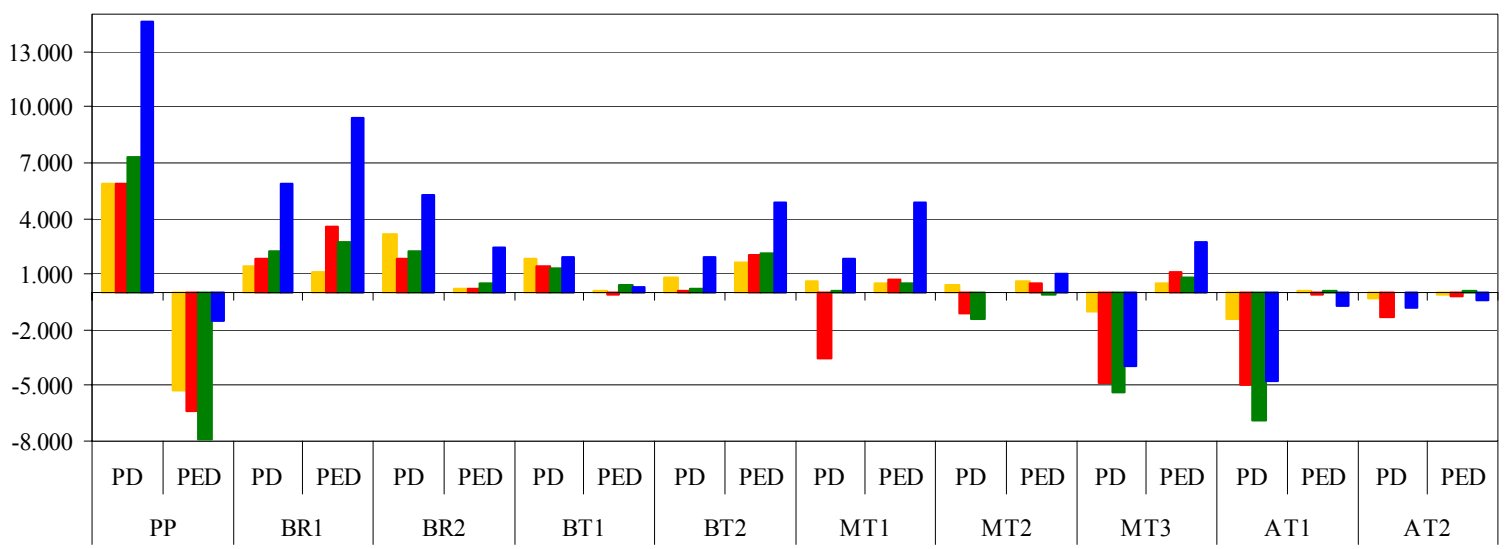

$\square 1990 \square 1995 \square 2000 \square 2005$

Legenda:

1 - $\mathrm{PP}=$ Produtos primários

2 - BR1 = Produtos agroflorestais

3 - BR2 = Produtos baseados em outros recursos

4 - BT1 = Têxtil/Vestuário/Calçados

5 - BT2 = Outros produtos de baixa tecnologia

Fonte: Secex - elaboração própria
$6-\mathrm{MT} 1=$ Produtos automotivos

7 - MT2 = Indústrias de processos (química)

8 - MT3 = Engenharia (máquinas e ferramentas)

9 - AT1 = Eletrônicos -Elétricos

10 - AT2 = Outros produtos de alta tecnologia

Compreender as relações comerciais sob a perspectiva tecnológica torna-se um tema mais atrativo quando o perfil das transações pode ser visualizado com base na caracterização por origem e destino geográfico dos fluxos. Além de possibilitar uma compreensão mais clara do tipo de relação que o país forma com outros grupos de nações, podem ser lançadas ilações sobre a evolução temporal do papel que uma determinada nação vem tendo sob o ponto de vista do maior ou menor grau de desenvolvimento dos parceiros comerciais.

O exame das estatísticas comerciais do Brasil com países-parceiros desenvolvidos (PD) e em desenvolvimento (PED) e por grupos tecnológicos, em anos selecionados (1990, 1995, 2000 e 2005), está apresentado na figura 4. 
A primeira impressão registrada se refere à dissonância entre o perfil das exportações com as importações de produtos básicos (que abarcam os produtos primários, agroflorestais e baseados em outros recursos). Por um lado fica claro que a maior dependência pelo lado das vendas recai sobre o grupo de PD, enquanto que por outro, as compras destes itens (que não são irrisórias) estão vinculadas, preponderantemente, aos PED. O aumento das exportações de produtos primários advém não somente do efeito da desvalorização cambial de 1999, mas, também, e, sobretudo, do aumento da demanda internacional de commodities, gerando, por conseqüência, crescimento em seus respectivos preços.

No que cabe aos fluxos de baixa tecnologia, alterações mais expressivas não são verificadas. Os fluxos do grupo de média tecnologia se destacam, em grande medida, pelo lado das importações originadas em PD. O diferencial entre os fluxos de média tecnologia advindos de PD com aqueles originários nos PED está bastante visível - entre 1995 e 2005 a diferença fica em torno de US\$10 bilhões para cada ano, o que não é desprezível. No que tange às exportações isso não ocorre de forma tão profunda. Até porque neste caso, a evolução que ocorre entre as vendas externas para PD e PED segue um mesmo sentido positivo. O crescimento das exportações deste grupo de produtos se dá, sobretudo, em 2005 quando ele é duplicado para os PD e triplicado para os PED.

O caso das transações pertinentes à alta tecnologia reserva um elemento interessante, tal como aconteceu com o grupo de produtos básicos - mas, agora num sentido geográfico inverso. Verifica-se que a grande dependência externa do Brasil em relação a esses produtos recai, de forma destacável, sobre os PD e em menor medida com os PED. Ademais, os diferenciais entre os montantes advindos dos PD foram sempre bastante superiores aos apresentados pelos fluxos originados de PED - o que reforça o caráter de relação dependente de produtos mais intensivos tecnologicamente no que se refere aos países mais desenvolvidos. Em relação às exportações, não se nota uma disparidade tão grande entre os fluxos enviados a cada um dos conjuntos de países, tal como ocorre com as importações. Os efeitos maiores são notados, sobretudo, em 2000 e 2005, quando esta categoria acompanha a evolução positiva e geral das vendas externas. Em suma, o Brasil depende de itens sofisticados advindos dos países mais ricos enquanto que as compras de produtos inferiores na escala de complexidade vêm dos parceiros, porventura, menos industrializados (tal como no caso dos produtos básicos). 


\section{Considerações Finais}

O intuito deste rápido exame foi apresentar um panorama amplo e descritivo do perfil e do comportamento do comércio exterior brasileiro a partir de uma perspectiva tecnológica. A compreensão das relações comerciais do Brasil na forma apontada é de extrema importância por se tratar de um país que apesar de deter uma estrutura industrial bem heterogênea e complexa, ainda depende de muitos desenvolvimentos tecnológicos externos. Ademais, no caso de países em desenvolvimento uma medida das relações tecnológicas com o exterior está, em grande medida, incorporada a bens e pode ser vista através do comércio de mercadorias. O Brasil sempre foi um país rotulado como grande produtor de commodities, e por muito tempo assim foi tratado perante a comunidade internacional. No entanto, este conceito já não pode ser aplicado. Quando a pauta comercial brasileira é observada, vê-se que se trata de um país que tem relações extremamente diversificadas com seus parceiros comerciais. Tanto se vende commodities de vários tipos, como também são exportados bens manufaturados com graus de industrialização e de incorporação tecnológica distintos cujos montantes não são desprezíveis.

A análise desenvolvida foi realizada a partir de quatro grupos tecnológicos: produtos básicos, baixa tecnologia, média tecnologia e alta tecnologia. Ademais, estes grupamentos foram desmembrados em outras categorias, possibilitando recuperar informações desagregadas. Em termos agregados, as estatísticas do comércio exterior brasileiro discriminadas por níveis tecnológicos reforçaram a noção prévia da posse de superávit em produtos básicos e de baixo grau de tecnologia incorporada, como também mostrou os déficits em grupos de produtos mais intensivos em tecnologia. De forma que as alterações cambiais indicaram a geração de impactos diferenciados sobre o comportamento dos grupos e das categorias, discriminadas por conteúdo tecnológico. 


\section{Referências Bibliográficas}

FURTADO, J. et al.(2002) Balanço de Pagamentos Tecnológico e Propriedade Intelectual. In Indicadores de Ciência e Tecnologia e Inovação - 2001/ Fapesp; [coordenação geral LANDI, F. R.] São Paulo: Fapesp.

GOMES, R., RODRIGUES, H. e CARVALHO, E.G (2005).; Balanço de Pagamentos Tecnológico: o perfil do comércio externo de produtos e serviços com conteúdo tecnológico", cap 7. In Indicadores de Ciência e Tecnologia e Inovação - 2004/ Fapesp; São Paulo: Fapesp.

LALL, S. (2000) The technological structure and performance of developing country manufactured exports, 1985-1998. Queen Elizabeth House - QEH Working Paper No 44.

PEREIRA, W. (2007) A estrutura produtiva da economia brasileira na década de 1990: o comércio exterior como uma lente privilegiada de análise. Ensaios FEE, vol. 28 nº 01. Porto Alegre.

Tecnologia e Comércio Internacional: exame das transações comerciais do Brasil sob a perspectiva tecnológica (2007). Dissertação (Mestrado). Departamento de Economia. Faculdade de Ciências Sociais Aplicadas, UFPR. Curitiba. 